\title{
A JUDICIALIZAÇÃO DO DANO MORAL COLETIVO DO PATRIMÔNIO CULTURAL
}

Dionis Mauri Penning Blank

Graduado em Direito e em Meteorologia, Especialista em Direito Ambiental e Mestre em Ciências e em Memória Social e Patrimônio Cultural. Atualmente, Assessor de Juiz de Direito na comarca de Pelotas e Professor na Faculdade Anhanguera de Pelotas. End. eletrônico: dionisblank@gmail.com

\section{RESUMO}

Esta pesquisa investiga a possibilidade jurídica de ocorrência do dano moral coletivo em virtude da destruição de bens culturais. O objetivo principal do trabalho foi comprovar ser admissível a configuração da responsabilidade civil ambiental pelo dano moral coletivo e, por consequência, do dever de indenizar a comunidade ou o grupo social, em razão das lesões sofridas pelo patrimônio cultural, sem prejuízo da reparação material. $\mathrm{O}$ corpo da pesquisa está estruturado na descrição da configuração da responsabilidade civil por dano moral coletivo e a possibilidade de condenar o ofensor ao pagamento de indenização, pelo dano causado aos bens culturais, destacando-se os precedentes ambientais e culturais e a análise de casos concretos dos Tribunais de Justiça estaduais do Brasil. Por resultado, tem-se a reparação por dano moral coletivo como instrumento de defesa do patrimônio cultural, com caráter pedagógico e punitivo.

Palavras-chave: Bens culturais. Indenização. Jurisprudência. 


\title{
THE JUDICIALIZATION OF THE MORAL COLLECTIVE MORAL DAMAGE OF THE CULTURAL HERITAGE
}

\begin{abstract}
This research investigates the legal possibility of occurrence of collective moral damages due to the destruction of cultural property. The main objective was to prove to be admissible configuration of liability for environmental damages collective and, therefore, the duty to compensate the community or social group, due to injuries sustained by cultural heritage, without prejudice to the repair materials. The body of research is structured in the description of the configuration of civil liability for damages collective and the possibility to order the offender to pay compensation, for damage to cultural property, highlighting the environmental and cultural precedents and analysis of concrete cases of the Courts Justice state of Brazil. In result, there is the compensation for damages collective to provide protection of cultural heritage, with pedagogical and punitive.
\end{abstract}

Keywords: Cultural property. Reparation. Jurisprudence.

\section{INTRODUÇÃO}

O tema exposto nesta pesquisa é incipiente sob o ponto de vista em que é abordado. A vinculação entre dano moral coletivo e bens culturais passa pela concepção da possibilidade da indenização pela violação do patrimônio cultural. O sentimento de desapreço ocasionado pelo dano coletivo a um bem cultural, que não possui apenas um valor histórico, entretanto, igualmente, artístico, científico e social, com enlace motivado pela identidade e memória, deve ser tutelado coletivamente, sem prejuízo das demais reparações.

Desse modo, o patrimônio cultural é constituído por bens compostos de significativo e particular valor para a comunidade, sendo verdadeiras referências materiais ou imateriais, representativas de fazer, ser e viver dos distintos grupos formadores da nação. Essa coletividade, ante uma transgressão ao patrimônio cultural, logicamente, poderá ser atingida em relação a seus valores intangíveis, em face, em especial, do estado coletivo 
de menosprezo, do sofrimento, da indignação e do descrédito ao direito.

Trata-se, enfim, do dano moral coletivo, vivenciado por um conjunto de indivíduos que suportam um prejuízo a um interesse comum, ou seja, ocorre o desrespeito a um determinado círculo de valores coletivos, violando a própria cultura, em seu caráter imaterial. Nesse sentido, a dupla função (punitiva e pedagógica) do dano moral (reparar o dano sofrido pelo ofendido e punir o ofensor), sob o prisma do dano moral coletivo, ganha outro contorno: aplicar um modelo de exemplaridade para a sociedade, na ótica da moralidade administrativa, conforme vêm decidindo os Tribunais na atualidade, em que pese a passos lentos.

A abordagem desta pesquisa é crítica na direção de afastar a compreensão de que o ideário contido no dano moral seria incompatível com a indeterminabilidade do sujeito passivo e com a indivisibilidade da violação e reparação, porquanto os novos fundamentos (solidários e humanistas) afastam o entendimento de uma teoria individualista. Além disso, a tutela passa a ser de interesses metaindividuais (direitos difusos), o que requer o reconhecimento da coletividade como sujeito de direito, carregada de atributos subjetivos.

Assim, é preciso tocar nas particularidades de direito material e processual (judicialização) relativas à configuração dos danos morais coletivos (responsabilidade objetiva, danos ao patrimônio cultural material e imaterial, prova do dano, quantificação do valor indenizatório e destinação de valores), relacionando os precedentes jurisprudenciais ambientais e culturais. Além disso, para atestar, de maneira segura e cristalina, a teoria trazida à baila nesta pesquisa, explicita-se a investigação dos concretos nos Tribunais de Justiça estaduais brasileiros, mediante análise criteriosa de toda a jurisprudência estadual existente, em nível de $2^{\circ}$ grau, sobre a problematização proposta neste estudo.

Por isso, o objetivo do trabalho foi evidenciar a possibilidade de ocorrência do dano moral coletivo, em razão de lesões sofridas pelo patrimônio cultural, utilizando como suporte os casos existentes na jurisprudência dos Tribunais de Justiça dos Estados do país, tratando o enfoque como uma inovação na tentativa de obstaculizar ou dificultar os ataques ao patrimônio cultural, bem como uma forma de reparar o dano (moral coletivo) pela falta e/ou ausência que o bem faria para a comunidade, que refletiria em um vazio na memória coletiva.

Para o alcance do objetivo mencionado, indispensável a aplicação do método de abordagem (ou raciocínio) hipotético-dedutivo, do método 
de procedimento (ou investigação) monográfico e as pesquisas bibliográfica, documental e explicativa, com base na técnica de análise de conteúdo. O corpo da pesquisa está estruturado no exame da jurisprudência, por meio do sítio eletrônico e busca de palavras-chave (patrimônio e cultural e dano e moral e coletivo), dos vinte e seis Tribunais de Justiça dos Estados e do Distrito Federal e Territórios brasileiros, no período de disponibilidade dos dados na internet até fevereiro do ano de 2012, inclusive.

\section{RESPONSABILIDADE CIVIL PELO DANO AO PATRIMÔNIO CULTURAL}

O patrimônio cultural, enquanto um direito difuso, tanto para o Poder Público como para os particulares, é sempre indisponível e deve ser preservado, em especial, tendo em conta as gerações do porvir. Dessa maneira, o direito de todos aos bens culturais diz respeito não apenas à guarda, preservação e proteção desses bens, mas também a sua promoção, nela se inserindo o direito de acesso e fruição pela coletividade em geral, diante de sua titularidade difusa.

Nesse sentido, o sujeito que, de qualquer modo, contribuir para a degradação do patrimônio cultural, por força da responsabilização civil, estará obrigado a reparar o dano, prioritariamente fazendo o patrimônio retornar ao estado anterior e, em caso de impossibilidade técnica de recuperação do bem, parcial ou total, tornando-se irreversíveis os danos causados, caberá a compensação pelos danos irrecuperáveis ou indenização em dinheiro, sem prejuízo da indenização pelos danos morais coletivos decorrentes.

Sobre essa matéria (ressarcimento do dano sofrido), Freitas ${ }^{1} \operatorname{traz}$ valiosos esclarecimentos, informando suas formas de ocorrência. Primeiro, a reparação in situ (restauração e recuperação), que seria a forma de reparação in natura e no local degradado (in situ). Observa-se que foi a Lei n. 9.985/2000 a primeira a diferenciar e conceituar os termos recuperação ${ }^{2}$ e restauração ${ }^{3}$, em seu Art. $2^{\circ}$. De qualquer sorte, a Constituição Federal de 1988 (CF/1988) determinou a prevalência da restauração em relação a

\footnotetext{
${ }^{1}$ FREITAS, 2011, p. 13-16.

${ }^{2}$ Inciso XIII - recuperação: restituição de um ecossistema ou de uma população silvestre degradada a uma condição não degradada, que pode ser diferente de sua condição original.

${ }^{3}$ Inciso XIV - restauração: restituição de um ecossistema ou de uma população silvestre degradada o mais próximo possível da sua condição original.
} 
qualquer outra forma de recuperação, ao determinar a necessidade de restaurar os processos ecológicos essenciais. Segundo, a compensação, que seria a forma por meio da qual se reconstitui ou melhora um dado outro bem ou sistema equivalente ao afetado, devendo ser permitida apenas nas hipóteses em que a reparação in natura e in situ (restauração e recuperação) forem, verdadeiramente, impossíveis (parcial ou totalmente) ou como medida que precede a indenização. Por fim, a terceira hipótese, concebida na indenização, como forma indireta de reparar o dano, sendo o dinheiro da indenização revertido ao Fundo de Reparação aos Interesses Difusos Lesados, que será visto adiante.

A autora, especificamente sobre a indenização, diz o seguinte:

A impossibilidade técnica da restauração ou da recuperação, total ou parcialmente, deve vir embasada em cabal demonstração desta irrecuperabilidade, de tal sorte que da análise do laudo técnico do órgão ambiental, dos pareceres dos assistentes técnicos das partes e do laudo do perito judicial, conforme o caso, o magistrado deve amparar aquele que, de fato, observe a reparação integral do meio ambiente.

Em outras palavras: se há alternativa técnica para que seja restaurado, ou mesmo recuperado, o meio ambiente, não é permitido ao magistrado (ou a quem quer que seja) optar pela compensação, valorando monetariamente o dano ambiental, sob pena de se afrontar o princípio da integral reparação do dano. O bem ambiental é de titularidade difusa e, portanto, indisponível ${ }^{4}$.

Nesse ponto, é preciso deixar muito claro, desde já, muito embora isso seja tratado pouco mais à frente, até porque na prática existem posicionamentos diversos sobre essa questão, conforme, aliás, acabou de ser visto, que os danos morais coletivos não têm o condão de afastar a condenação pela reparação também por dano materiais ${ }^{5}$, quando ocorridos, principalmente, porque no Direito Ambiental vige o princípio da restitutio in integrum (reparação integral).

A reparação dos prejuízos causados ao patrimônio cultural deve ser sempre integral, priorizando-se a sua recomposição no estado em que se encontrava antes da ocorrência do dano (máxima coincidência com a situação anterior). Além dos danos materiais há hipóteses em que será viável também o pedido de reparação dos danos

\footnotetext{
${ }^{4}$ FREITAS, 2011, p. 16.

${ }^{5}$ Súmula n. 37 do Superior Tribunal de Justiça: São cumuláveis as indenizações por dano material e dano moral oriundos do mesmo fato.
} 
morais coletivos [...].

Tendo em vista que o Brasil adotou a teoria integral do dano ambiental, qualquer lesão causada ao meio ambiente há que ser recuperada em sua integralidade e qualquer disposição legal que pretenda limitar ou tarifar o montante indenizatório será inconstitucional ${ }^{6}$.

Sobre a responsabilidade civil, frisa-se ainda sua dupla função: a) assegurar às pessoas o direito de segurança, de maneira que todos se sintam compelidos a respeitar o patrimônio alheio, pois é sabido que deverão responder por eventual dano que causarem; e b) servir de sanção de natureza compensatória, mediante a reparação do dano causado. Ademais, sobre ela, cabe a ressalva de que é independente da criminal, segundo preceitua o Art. $935^{7}$ do Código Civil. Em razão disso, o sujeito que deteriora bens de valor cultural pode ser absolvido no juízo criminal em face da prática de um fato inicialmente considerado delituoso e, todavia, ser obrigado à reparação do dano no juízo cível. O agente, da mesma forma, pode ser civilmente obrigado à reparação do dano, muito embora o fato causador da lesão seja penalmente atípico. Por isso, via de regra a responsabilidade do ofensor em uma esfera não implica a responsabilidade em outra.

\subsection{Responsabilidade objetiva}

A responsabilidade pela violação das normas de acautelamento do patrimônio cultural é objetiva, isto é, independe da existência de culpa, nos termos do que estabelece o Artigo 14, $\S 1^{\circ}$, da Lei n. 6.938/1981, cumulado com o Artigo 927, parágrafo único, do Código Civil, literalmente:

Art. 14 - Sem prejuízo das penalidades definidas pela legislação federal, estadual e municipal, o não cumprimento das medidas necessárias à preservação ou correção dos inconvenientes e danos causados pela degradação da qualidade ambiental sujeitará os transgressores:

\section{$[\ldots]$}

$\S 1^{\circ}$ Sem obstar a aplicação das penalidades previstas neste artigo, é o poluidor obrigado, independentemente da existência de culpa, a indenizar ou reparar os danos

\footnotetext{
$\overline{{ }^{6} \text { MIRANDA, 2006, p. } 289 .}$

${ }^{7}$ Art. 935 - A responsabilidade civil é independente da criminal, não se podendo questionar mais sobre a existência do fato, ou sobre quem seja o seu autor, quando estas questões se acharem decididas no juízo criminal.
} 
causados ao meio ambiente e a terceiros, afetados por sua atividade. O Ministério Público da União e dos Estados terá legitimidade para propor ação de responsabilidade civil e criminal, por danos causados ao meio ambiente.

$[\ldots]$

Art. 927 - Aquele que, por ato ilícito (arts. 186 e 187), causar dano a outrem, fica obrigado a repará-lo.

Parágrafo único. Haverá obrigação de reparar o dano, independentemente de culpa, nos casos especificados em lei, ou quando a atividade normalmente desenvolvida pelo autor do dano implicar, por sua natureza, risco para os direitos de outrem.

Miranda ${ }^{8}$ salienta que, ao contrário da regra geral, em que a responsabilidade civil decorre da culpa, quando há que se provar que houve uma conduta ilícita que deu origem ao prejuízo, em se tratando de lesão ao patrimônio cultural, é necessário, apenas, o nexo de causalidade entre o ato e o dano para que haja a responsabilidade civil do agente causador, ainda que decorra a lesão de ato ilícito ou risco. Desse modo, basta o nexo causal entre a ação ou a omissão do agente e o dano decorrente para que subsista a obrigação de repará-lo.

Milaré $^{9}$ defende que, tratando-se de tutela ambiental, a responsabilidade objetiva vincula-se à "[...] teoria do risco integral (como descreveu antes o outro autor), que atende à preocupação de se estabelecer um sistema o mais rigoroso possível, ante o alarmante quadro de degradação que se assiste não só no Brasil, mas em todo o mundo".

Para a teoria do risco integral, a responsabilidade civil objetiva necessita apenas da observação do dano sofrido e nexo causal entre a atividade e a lesão, não apresentando temperamentos e formas excludentes de responsabilização, como culpa exclusiva ou concorrente da vítima, ação de terceiros, caso fortuito ou força maior. Para os partidários desta teoria, a simples existência da atividade já é reputada como condição para o evento lesivo. Por evidente, a adoção dessa variação à teoria do risco concreto "expressa a preocupação da doutrina em estabelecer um sistema mais rigoroso" acerca da incidência da responsabilidade civil objetiva por danos ambientais. Segundo a teoria do risco integral, um posto de combustíveis, que, cumpridor de todas as exigências jurídicas e ambientais, atingido por um raio, venha a explodir, ocasionando um derramamento de combustíveis e óleos em cursos d'água, deverá ter

\footnotetext{
${ }^{8}$ MIRANDA, 2006, p. 259.

${ }^{9}$ MILARÉ, 2007, p. 897, 898.
} 
o seu empreendedor responsabilizado ${ }^{10}$.

A Teoria do Risco Integral é a mais enérgica e aceita jurisprudencialmente, porque a reparação do dano é devida somente pelo fato de existir a atividade da qual adveio o dano, não admitindo excludentes de responsabilidade como a força maior, o caso fortuito, a ação da própria vítima ou de terceiros. Por lógico, existem outras teorias aplicáveis, como a Teoria do Risco Criado e a Teoria do Risco Proveito, que se diferenciam entre si, pois a primeira não leva em consideração se o causador do dano auferiu proveito com a atividade, situação sequer questionável na Teoria do Risco Integral.

Na verdade, conjugando-se o conceito amplo ou holístico que, contemporaneamente, se vem atribuindo ao meio ambiente, com a concepção arejada do patrimônio cultural, resta justificada a conclusão de que também neste campo se deve priorizar a responsabilidade objetiva, como técnica eficiente para a prevenção e a correção dos danos e abusos perpetrados contra os bens de natureza material e imaterial que compõem o acervo cultural do povo brasileiro ${ }^{11}$.

Enfim, a adoção da responsabilidade objetiva, no que diz com os danos causados ao patrimônio cultural, implica, em síntese, nas seguintes consequências de ordem prática, conforme descreve Miranda ${ }^{12}$ : a) irrelevância da intenção danosa; b) irrelevância da mensuração do subjetivismo; c) irrelevância da licitude da atividade; e d) inaplicabilidade do caso fortuito e da força maior como excludentes de responsabilidade. Registre-se a existência de posicionamento jurisprudencial pelo Superior Tribunal de Justiça (STJ), reconhecendo a aplicação da responsabilidade civil objetiva aos danos cometidos contra o patrimônio cultural:

MEIO AMBIENTE. Patrimônio cultural. Destruição de dunas em sítios arqueológicos. Responsabilidade civil. Indenização.

$\mathrm{O}$ autor da destruição de dunas que encobriam sítios arqueológicos deve indenizar pelos prejuízos causados ao meio ambiente, especificamente ao meio ambiente natural (dunas) e ao meio ambiente cultural (jazidas arqueológicas com cerâmica indígena da Fase Vieira).

\footnotetext{
${ }^{10}$ CARVALHO, 2008, p. 117, 118.

${ }^{11}$ MIRANDA, 2009, p. 244.

${ }^{12}$ MIRANDA, 2006, p. 260.
} 
Recurso conhecido em parte e provido. (REsp 115599 / RS, Quarta Turma, Rel. Min. Ruy Rosado de Aguiar, Julgado em: 27/06/2002).

\title{
2.2 Danos ao patrimônio cultural material e imaterial
}

Os danos ao patrimônio cultural material brasileiro são bastante cotidianos e se caracterizam das mais diversas formas. Em sua ampla maioria decorrem da utilização nociva da propriedade e de condutas (comissivas ou omissivas, culposas ou dolosas) do Poder Público ou de particulares. Miranda ${ }^{13}$ enfatiza que:

\begin{abstract}
A destruição, deterioração, inutilização de prédios e documentos históricos, a descaracterização e o abandono de edificações tombadas, a demolição às pressas e às ocultas de bens inventariados ou em processo de tombamento, a pichação de sítios arqueológicos rupestres, a extração e o comércio clandestinos de fósseis e bens de valor arqueológico, a subtração e o comércio descontrolado de imagens sacras coloniais, a explosão de grutas que guardam vestígios arqueológicos e paleontológicos para exploração de recursos minerais, a pichação de monumentos urbanos, as construções em frontal desrespeito às normas de ordenamento urbano, a poluição visual em cidades históricas e turísticas, o descaso com bibliotecas, museus, teatros, cinemas e demais espaços destinados às manifestações culturais, todas estas condutas são exemplos da enorme e variada gama de ações lesivas ao patrimônio cultural material brasileiro e que devem ser objeto de especial atenção dos operadores do direito, a quem toca lançar mão dos meios preventivos e reparadores existentes no ordenamento jurídico vigentes.
\end{abstract}

A título ilustrativo, a interessante argumentação, muito bem fundamentada e esclarecedora, na posição do Superior Tribunal de Justiça quanto ao dano material ao patrimônio cultural, que vale a transcrição:

ADMINISTRATIVO E URBANÍSTICO. BRASÍLIA. PLANO PILOTO E REGIÃO ADMINISTRATIVA DO CRUZEIRO. PATRIMÔNIO HISTÓRICO E ARTÍSTICO NACIONAL. TOMBAMENTO. PATRIMÔNIO MUNDIAL. INSTALAÇÃO DE GRADES EM TORNO DOS PILOTIS DOS EDIFÍCIOS RESIDENCIAIS NAS SUPERQUADRAS. INCOMPATIBILIDADE COM O PROJETO ORIGINAL. INTERPRETAÇÃO DOS ARTS. 17 E 18 DO DL 25/1937 E DA CONVENÇÃO

${ }^{13}$ MIRANDA, 2006, p. 271. 
RELATIVA À PROTEÇÃO DO PATRIMÔNIO MUNDIAL, CULTURAL E NATURAL.

$[\ldots]$

2. Em razão do singular conjunto arquitetônico e do revolucionário conceito urbanístico-paisagístico (sobretudo a organização em superquadras povoadas por prédios sustentados por pilotis), o Plano-Piloto de Brasília foi, em 1990, tombado pelo Iphan, nos termos do Decreto-Lei ${ }^{\circ} 25$, de 30 de novembro de 1937, estatuto federal que protege o patrimônio histórico e artístico nacional.

$[\ldots]$

9. A Convenção Relativa à Proteção do Patrimônio Mundial, Cultural e Natural tem aplicabilidade judicial direta no Brasil, seja porque seus princípios gerais e obrigações, mesmo os aparentemente mais abstratos e difusos, iluminam o sistema constitucional e legal brasileiro e com ele dialogam, em perfeita harmonia, coerência e complementaridade, seja por ser inadmissível que o País negocie, assine e ratifique tratados internacionais para em seguida ignorá-los ou só aplicá-los de maneira seletiva, cosmética ou retórica.

$[\ldots]$

15. Nos processos judiciais que envolvam monumentos, conjuntos, locais notáveis, formações geológicas e fisiográficas, e outros sítios inscritos como patrimônio mundial, o Poder Judiciário brasileiro não só pode, como deve, fazer valer diretamente a Convenção, já que seu texto vincula os Estados-Parte ao ponto de influenciar e orientar as decisões de seus juízes.

$[\ldots]$

24. Recurso Especial provido, para reconhecer que o Distrito Federal violou o art. 17 do Decreto-Lei n ${ }^{\circ}$ 25/1937, bem como as obrigações internacionais do Brasil, das quais é devedor-solidário, decorrentes da Convenção Relativa à Proteção do Patrimônio Mundial, Cultural e Natural, em particular as estatuídas nos arts. $4^{\circ}$ e $5^{\circ}$, "d". (STJ, REsp 840918 / DF, Segunda Turma, Rel. Min. Eliana Calmon, Julgado em: $14 / 10 / 2008)$.

Ademais, assim como ocorre com os bens culturais materiais, os bens imateriais podem ser alvo de ações danosas, que, igualmente, culminam na responsabilidade civil do agente degradador. Cabe a referência, de acordo com Miranda ${ }^{14}$, de que não é o simples fato, por exemplo, de uma determinada manifestação cultural estar arraigada nos costumes de um povo há décadas ou séculos que o Poder Público, necessariamente, terá de preservá-la e promovê-la, até porque "As manifestações culturais não

${ }^{14}$ MIRANDA, 2006, p. 266. 
são direitos absolutos e, no confronto com outros direitos, há necessidade de se buscar a compatibilização das mesmas com os demais valores juridicamente protegidos".

Nesse particular, bastante interessante o confronto estabelecido entre a tutela do meio ambiente cultural e do meio ambiente natural que ocorreu no Estado de Santa Catarina, em que entidades protetoras dos animais se insurgiram em desfavor da "Farra do Boi", conhecida manifestação cultural de algumas comunidades daquele Estado, de origem açoriana. De um lado, havia a proteção constitucional às manifestações culturais e, de outro, a proteção ambiental que proíbe a prática da violência e crueldade contra animais.

Tal situação foi apreciada pelo Poder Judiciário, chegando ao Supremo Tribunal Federal (STF), onde ocorreu diversidade de entendimentos dos Ministros, no momento do julgamento do Recurso Extraordinário (RE) n. 153.531, em 13 de março de 1998, assim ementado:

COSTUME - MANIFESTAÇÃO CULTURAL - ESTÍMULO - RAZOABILIDADE - PRESERVAÇÃO DA FAUNA E DA FLORA - ANIMAIS - CRUELDADE. A obrigação de o Estado garantir a todos o pleno exercício de direitos culturais, incentivando a valorização e a difusão das manifestações, não prescinde da observância da norma do inciso VII do artigo 225 da Constituição Federal, no que veda prática que acabe por submeter os animais à crueldade. Procedimento discrepante da norma constitucional denominado 'farra do boi'.

A fundamentação vencida, de Ministro Maurício Corrêa, inclinou-se no juízo da proporcionalidade e da razoabilidade, já que, tendo em conta uma nítida colisão de princípios acauteladores de direitos fundamentais, consistentes na ecologia e na cultura, não percebendo como garantia da primeira a proibição da segunda, sendo suficiente o controle do abuso. Esse voto se fundou em parecer técnico elaborado por antropólogos e sociólogos, que privilegiaram a prática do costume como elemento de identidade cultural.

Sob outra perspectiva, a tese vencedora, levantada pelo Ministro Marco Aurélio, fundamentou que a manifestação cultural deve ser estimulada; entretanto, a prática cruel não. Houve a ponderação de que, admitida a "Farra do Boi", em que uma multidão ensandecida vai atrás do animal para procedimento apavorante, não há poder de polícia que consiga coibilo. 
Desse modo, por maioria (três votos a um), a Segunda Turma do STF deu provimento ao RE, ao efeito de obrigar o Estado de Santa Catarina a efetivar todas as medidas necessárias para proibir totalmente a prática dessa manifestação cultural naquele Estado.

Miranda $^{15}$, nessa ótica, chama atenção a outras situações que envolvem as manifestações culturais, quanto ao condicionamento dos locais onde as elas devem ser exercidas, sendo comum proibições de eventos multitudinários e causadores de grandes impactos ambientais em locais protegidos ou impróprios para tal finalidade. Ainda destaca o referido autor que o Poder Público deve condicionar a realização ou impedir tais manifestações, não sendo admissível, por exemplo, "[...] que uma escola de samba (manifestação cultural) com milhares de componentes e acompanhada por possantes caminhões de som transitem pelas estreitas ruas de uma cidade colonial tombada, ou por uma área urbana hospitalar"16, cabendo, inclusive, o acesso ao Poder Judiciário para coibir abusos.

\subsection{Danos morais coletivos}

A CF/1988 alcançou a reparação por dano moral à condição de direito fundamental de todo o cidadão ${ }^{17}$, e a Lei da Ação Civil Pública (LACP) estabeleceu expressamente a possibilidade de responsabilização por danos patrimoniais e morais causados ao meio ambiente e a qualquer outro interesse coletivo ou difuso, como foi apresentado anteriormente. Assim, a disposição legal citada consagrou no ordenamento jurídico brasileiro a reparação do dano ambiental coletivo ou difuso em toda a sua extensão, inclusive no tocante à sua esfera não patrimonial.

O dano moral coletivo é aquele experimentado por um grupo de pessoas, as quais sofrem um prejuízo a um interesse comum. É uma violação do círculo de valores de uma determinada comunidade. Cafferatta ${ }^{18}$ articula que:

[...] o interesse difuso ou comum é afetado quando a qualidade de vida sofre o im-

\footnotetext{
${ }^{15}$ MIRANDA, 2006, p. 266.

${ }^{16}$ MIRANDA, 2006, p. 266, 267.

${ }^{17}$ Art. $5^{\circ}$ - Todos são iguais perante a lei, sem distinção de qualquer natureza, garantindo-se aos brasileiros e aos estrangeiros residentes no País a inviolabilidade do direito à vida, à liberdade, à igualdade, à segurança e à propriedade, nos termos seguintes: [...].

$\mathrm{V}$ - é assegurado o direito de resposta, proporcional ao agravo, além da indenização por dano material, moral ou à imagem.
}

${ }^{18}$ CAFFERATTA, 2005, p. 24. 
pacto da atividade humana individual ou coletiva. $\mathrm{O}$ dano ambiental recai então no patrimônio cultural se os bens lesionados são obra artística, paisagística, urbanística ou arquitetônica (além de outras e dos bens imateriais), que é comum a uma coletividade, ocasionando um dano moral coletivo ao privar o grupo social das sensações e satisfações espirituais indispensáveis para a manutenção e melhora da qualidade de vida $^{19}$. (tradução própria)

Desse modo, a coletividade, em face de um prejuízo causado ao patrimônio cultural, evidentemente pode ser afetada quanto a seus valores imateriais, face ao sentimento coletivo de desapreço, de intranquilidade, de angústia, de indignação e de demonstração de menoscabo ao direito. Logicamente, nem toda a violação do patrimônio cultural resultará na configuração do dano moral coletivo, porque esses surgem nos exatos casos em que a lesão causada seja marcada pela destacada significância, superando os limites da tolerabilidade social, afrontando relações de aceitabilidade média ou afetando a tranquilidade anímica e espiritual da coletividade, a qual tem modificada negativamente sua qualidade de vida, vendo seus valores mais caros afetados.

[...] em caso de danos graves ao patrimônio cultural (tais como a lesão significativa ou ruína de bens históricos, o impedimento arbitrário da realização de uma festa tradicional ou de uma importante partida de futebol, a privação injusta e duradoura do acesso e fruição de uma imagem sacra de grande valor histórico, decorrente de sua subtração; a danificação irreparável ou de difícil e custosa reparação de um local especialmente protegido etc.), considerando-se o valor do bem para a coletividade, o grau de repercussão do evento danoso, representativo de uma ofensa ao sentimento coletivo, é de se pleitear a indenização pelos danos extrapatrimoniais (morais) decorrentes, ante o sentimento geral de indignação e de dor, de menoscabo pela ordem jurídica, sem prejuízo, obviamente, das medidas necessárias à recuperação ou reparação material dos bens afetados, quando possível ${ }^{20}$.

Nesse sentido, a aplicação da responsabilidade civil em razão de danos morais coletivos é, certamente, uma sanção garantidora do restabe-

\footnotetext{
${ }^{19}$ Así, el interés difuso o común resulta afectado cuando la calidad de vida sufre el impacto de la actividad humana individual o colectiva. El daño ambiental recae entonces en el patrimonio cultural si los bienes dañados son la obra artística, paisajística, urbanistica o arquitectónica, que es común a una colectividad, ocasionando un daño moral colectivo al privar a un grupo social de lãs sensaciones $y$ datisfacciones espirituales indispensables para el mantenimiento y mejora de la calidad de vida.

${ }^{20}$ MIRANDA, 2009, p. 234, 235.
} 
lecimento da dignidade social, ao mesmo tempo em que funciona como medida de caráter preventivo, por representar a ampliação da possibilidade de responsabilização do degradador. Enfim, revela-se com um inovador instrumento, a fim de garantir maior proteção aos bens culturais, visando a obstaculizar ou, ao menos, reduzir as violações causadas a esses bens.

Outro aspecto importante diz respeito à prova do dano, inclusive porque há como objeto nesta pesquisa bens de natureza imaterial. Sobre isso, é conveniente dizer que, diante da tutela de direitos transindividuais, não devem existir critérios rígidos ou ritualísticos para se deduzir a existência de danos morais coletivos, desde que seja verificada pelo julgador a existência de uma ofensa antijurídica significante, que ultrapassa os limites da tolerabilidade social.

Nesses casos, presume-se (presunção hominis ou facti ou de fato) a ocorrência de dano extrapatrimonial (damnum in re ipsa ou dano moral puro), que deriva inexoravelmente do simples fato ofensivo, segundo as regras da experiência comum: na concepção moderna do ressarcimento por dano moral, prevalece a responsabilização do agente por força do simples fato da violação, de modo a se tornar desnecessária a prova do prejuízo em concreto, ao contrário do que ocorre com o dano material; provados os fatos e as circunstâncias para o reconhecimento do dano extrapatrimonial, não se exige a prova do desconforto, da dor ou da aflição, que são admitidos mediante um juízo de experiência, conforme ensina Miranda ${ }^{21}$.

Além disso, calha falar acerca da quantificação dos danos morais coletivos. A valoração desses danos, conquanto não seja uma tarefa simples, pode ser alcançada da mesma forma que ocorre em sede de reparação por danos morais individuais. Segundo descreve Leite $^{22}$, o arbitramento do valor devido (quantum debeatur) deve ficar ao arbítrio do magistrado no curso da ação civil pública ou da ação popular, o qual definirá o valor da indenização de acordo com os elementos verificados no caso concreto.

Sobre essa temática, ressalto que, praticamente duas décadas atrás, o egrégio Tribunal de Justiça do Estado do Rio Grande Sul preocupou-se com a demarcação do valor a ser fixado a título de indenização por dano moral. Logicamente, a fixação se refere ao dano moral individual, mas serve de base até os dias atuais:

\footnotetext{
${ }^{21}$ MIRANDA, 2009, p. 245.

${ }^{22}$ LEITE, 2003, p. 303.
} 
DANO MORAL. SUA MENSURACAO. NA FIXACAO DO 'QUANTUM' REFERENTE A INDENIZACAO POR DANO MORAL, NAO SE ENCONTRANDO NO SISTEMA NORMATIVO BRASILEIRO METODO PRATICO E OBJETIVO, O JUIZ HA QUE CONSIDERAR AS CONDICOES PESSOAIS DE OFENSOR E OFENDIDO; GRAU DE CULTURA DO OFENDIDO; SEU RAMO DE ATIVIDADE; PERSPECTIVAS DE AVANÇO E DESENVOLVIMENTO NA ATIVIDADE QUE EXERCIA, OU EM OUTRO QUE PUDESSE VIR A EXERCER; GRAU DE SUPORTABILIDADE DO ENCARGO PELO OFENSOR, E OUTROS REQUISITOS QUE, CASO A CASO, POSSAM SER LEVADOS EM CONSIDERAÇÃO. REQUISITOS QUE HA DE VALORAR COM CRITERIO DE JUSTICA, COM PREDOMINIO DO BOM SENSO, DA RAZOABILIDADE E DA EXEQUIDADE DO ENCARGO A SER SUPORTADO PELO DEVEDOR. “QUANTUM” QUE NEM SEMPRE DEVERA SER INFERIOR AO DO DANO PATRIMONIAL. EIS QUE A AUTOESTIMA, A VALORACAO PESSOAL, O EGO, SAO VALORES HUMANOS CERTAMENTE MAIS VALIOSOS QUE OS BENS MERAMENTE MATERIAIS OU ECONOMICOS. INCONFORMIDADE COM A SENTENÇA QUE FIXOU O MONTANTE DA INDENIZACAO POR DANO MORAL. IMPROVIMENTO DO APELO DA DEVEDORA. (sic) (Apelação Cível N. 592066575, Sexta Câmara Cível, Tribunal de Justiça do RS, Relator: Osvaldo Stefanello, Julgado em 23/11/1993)

À falta de medida aritmética, e ponderadas as funções satisfatória e punitiva, serve à fixação do montante da indenização o prudente arbítrio do juiz, tendo em conta certos requisitos e condições, os quais, conforme elucida a doutrina, ficam ancorados na intensidade da responsabilidade pelo ato danoso omisso ou comissivo, na situação econômica do ofensor, no grau de proveito obtido pelo agente, na extensão (repercussão) do dano e grau, tempo e custo de reversibilidade, bem como considerando a função de desestímulo para a prática de atos semelhantes (caráter sancionador e pedagógico).

Por fim, igualmente é importante comentar acerca da destinação dos valores da indenização.

A LACP trouxe, por meio de seu Art. 13 que, existindo condenação em dinheiro, a indenização pelo dano causado reverterá a um fundo gerido por um Conselho Federal ou por Conselhos Estaduais de que participarão necessariamente o Ministério Público e representantes da comunidade, sendo seus recursos destinados à reconstituição dos bens lesados. 
Seu $\S 1^{023}$ deliberou que, enquanto o fundo não for regulamentado, o dinheiro ficará depositado em estabelecimento oficial de crédito, em conta com correção monetária ${ }^{24}$.

Dessa maneira, os valores arrecadados em razão da condenação judicial pelo cometimento de danos morais coletivos decorrentes de lesões ao patrimônio cultural deverão ser destinados para um dos fundos de direitos difusos mencionados. Dependendo do caso concreto, o fruto da condenação poderá ser destinado a fundos estaduais.

O Artigo 13, $\S 1^{\circ}$, da LACP previu que, enquanto o fundo não fosse regulamentado, o dinheiro ficaria depositado. Isso ocorreu até 1986, quando o Decreto n. 93.302 regulamentou o fundo. Esse diploma sofreu algumas alterações, tendo a Lei n. 9.008/1995 criado, na estrutura organizacional do Ministério da Justiça, o Conselho Federal de que trata o artigo citado da LACP.

\section{A Lei n. 9.008/1995 elucida, no seu Artigo $1^{\circ}, \S 1^{\circ}$, que o Fundo de Defesa dos Direitos Difusos (FDD):}

[...] tem por finalidade a reparação dos danos causados ao meio ambiente, ao consumidor, a bens e direitos de valor artístico, estético, histórico, turístico, paisagístico, por infração à ordem econômica e a outros interesses difusos e coletivos.

Os parágrafos $2^{025}$ e $3^{026}$ do artigo citado descrevem particulari-

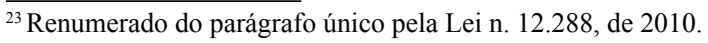

${ }^{24} \mathrm{O} \S 2^{\mathrm{o}}$ do referido art. dispõe que: "Havendo acordo ou condenação com fundamento em dano causado por ato de discriminação étnica nos termos do disposto no art. 1ำ desta Lei, a prestação em dinheiro reverterá diretamente ao fundo de que trata o caput e será utilizada para ações de promoção da igualdade étnica, conforme definição do Conselho Nacional de Promoção da Igualdade Racial, na hipótese de extensão nacional, ou dos Conselhos de Promoção de Igualdade Racial estaduais ou locais, nas hipóteses de danos com extensão regional ou local, respectivamente". (Incluído pela Lei n. 12.288, de 2010).

${ }^{25} \S 2^{\circ}$ Constituem recursos do FDD o produto da arrecadação:

I - das condenações judiciais de que tratam os arts. 11 e 13 da Lei ${ }^{\circ} 7.347$, de 1985;

II - das multas e indenizações decorrentes da aplicação da Lei $\mathrm{n}^{\circ} 7.853$, de 24 de outubro de 1989, desde que não destinadas à reparação de danos a interesses individuais;

III - dos valores destinados à União em virtude da aplicação da multa prevista no art. 57 e seu parágrafo único e do produto da indenização prevista no art. 100, parágrafo único, da Lei $\mathrm{n}^{\circ} 8.078$, de 11 de setembro de 1990;

IV - das condenações judiciais de que trata o $\S 2^{\circ}$ do art. $2^{\circ}$ da Lei $n^{\circ} 7.913$, de 7 de dezembro de 1989 ;

V - das multas referidas no art. 84 da Lei $n^{\circ} 8.884$, de 11 de junho de 1994;

VI - dos rendimentos auferidos com a aplicação dos recursos do Fundo;

VII - de outras receitas que vierem a ser destinadas ao Fundo;

VIII - de doações de pessoas físicas ou jurídicas, nacionais ou estrangeiras.

${ }^{26} \S 3^{\circ}$ Os recursos arrecadados pelo FDD serão aplicados na recuperação de bens, na promoção de eventos educativos, científicos e na edição de material informativo especificamente relacionados com
} 
dades sobre a constituição de recursos do FDD.

Nesse contexto, Avila ${ }^{27}$ observa que há ambiguidade no texto do Artigo 13 da LACP, indicando que ele dá a falsa ideia de que ao fundo pode ser transferida a obrigação de reparação do dano, quando diz que "[...] recursos destinados à reconstituição dos bens lesados". Segundo ela, o fundo compensa e não repara, visto que o objetivo fim dele é concretizar medida compensatória de dano ecológico causado e provado. Além disso, descreve que houve desvirtuamento da finalidade do artigo, pois abriu a possibilidade de, em nome da compensação ambiental, criar-se verba extraorçamentária para modernização administrativa (Artigo $1^{\circ}, \S 3^{\circ}$, da Lei n. 9.008/1995).

Desse modo, seguindo a linha de pensamento da autora ${ }^{28}$, o fundo revela duas deficiências básicas, consistentes na ausência de uma clara destinação dos recursos recolhidos e na falta de uma estratégia legal para a gerência de seus recursos. Assim, a autora faz algumas críticas que redundariam em alteração legislativa: a) o fundo encarna um dispositivo de direito financeiro, que prevê um ente contábil diferenciado, criado a partir da LACP, mas não está previsto na lei que o regulamentou a subdivisão da conta-mãe em diversas contas voltadas cada qual para as diferentes tutelas; b) não há previsão legal determinando a utilização de recursos do fundo no território que originou os recursos, ou seja, o local do dano, divergindo nisso a doutrina e a jurisprudência; c) conceder maior autonomia ao conselho gestor que está praticamente limitado à aplicação de projetos apresentados e expedição de cartilhas; d) supressão da permissão legal do $\S 3^{\circ}$, do Artigo $1^{\circ}$, da Lei n. 9008/1995, para utilização dos recursos do fundo na modernização administrativa dos órgãos públicos; e) possibilidade de utilização dos fundos para situações emergenciais, a fim de evitar o agravamento do dano, enquanto não é apurada a autoria ou a questão está em discussão judicial; e f) criação de fundos de indenização para atender necessidades ambientais, como tendência moderna para solucionar os danos ambientais, vistos esses sob o prisma da solidariedade.

De qualquer sorte, até em razão da parca utilização da ferramenta que esta pesquisa tem por objeto, as discussões acerca desse instituto, realmente controverso, ainda não chegaram a um nível de efervescência para

a natureza da infração ou do dano causado, bem como na modernização administrativa dos órgãos públicos responsáveis pela execução das políticas relativas às áreas mencionadas no $\S 1^{\circ}$ deste artigo.

${ }^{27}$ AVILA, 2011, p. 3.

${ }^{28}$ AVILA, 2011, p. 10, 11. 
causar a impossibilidade de transposição de suas barreiras.

Em termos de Rio Grande do Sul, a jurisprudência tem se inclinado a recolher o valor da condenação em dinheiro ao Fundo de Defesa dos Direitos Difusos, in verbis:

APELAÇÃO CÍVEL. DIREITO AMBIENTAL. AÇÃO CIVIL PÚBLICA. RESPONSABILIDADE CIVIL POR DANO AMBIENTAL. CORTE IRREGULAR DE ÁRVORES NATIVAS. QUEIMADA EM CAMPO NATIVO. COMPETÊNCIA DA PATRAM PARA LAVRATURA DE AUTO DE INFRAÇÃO AMBIENTAL. RESPONSBILIDADE OBJETIVA. COMPROVAÇÃO DOS DANOS. REPLANTIO DE MUDAS. INDENIZAÇÃO. MANUTENÇÃO DO QUANTUM. CORREÇÃO MONETÁRIA INCIDENTE A PARTIR DA SENTENÇA. 1. A Brigada Militar, no exercício de polícia ostensiva de proteção ambiental, é competente para lavratura de auto de constatação de infração ambiental, conforme inc. II do art. 27 da Lei n ${ }^{\circ}$ 10.330/94. 2. A ação civil pública é meio processual hábil à busca da tutela jurisdicional de interesses essenciais à comunidade como um todo, dentre eles, a preservação ao meio ambiente equilibrado, direito constitucionalmente garantido (artigo $225 \mathrm{da} \mathrm{CF} / 88$ ). Assim, a ação civil pública tem por escopo, entre outros, responsabilizar os causadores de danos ao meio ambiente (art. $1^{\circ}$, I, da Lei $n^{\circ} 7.347 / 85$ ) e recuperar o ambiente degradado, com o que se preocupou expressamente a Constituição de 1988 (art. 225). Não se discute que a responsabilidade do requerido neste tipo de ação é objetiva. 3 . Comprovada a ocorrência de degradação ambiental. Os autos de infração, laudos periciais, boletins e notificações constantes dos inquéritos civis carreados aos autos constituem elementos de conviç̧ão decisivos ao desate da lide, ainda mais quando não infirmados pelo demandado. 4. De ser mantida a obrigação de replantio contemplada no comando sentencial, porquanto de acordo com o que estabelece o art. $8^{\circ}$ da Lei ${ }^{\circ}$ 9.519/92. 5. Manutenção do montante pecuniário da condenação imposta ao réu, a ser recolhido ao Fundo de Defesa dos Direitos Difusos. 6. Correção monetária pelo IGP-M a incidir a partir da data da sentença que arbitrou o montante da condenação em pecúnia imposta ao réu. APELAÇÃO PARCIALMENTE PROVIDA. UNÂNIME. (Apelação Cível Nº 70025691387, Segunda Câmara Cível, Tribunal de Justiça do RS, Relator: Miguel Ângelo da Silva, Julgado em 29/04/2009).

\section{PRECEDENTES AMBIENTAIS E CULTURAIS}

A produção relativa à configuração da responsabilidade civil, em decorrência de danos morais coletivos ocasionados por lesões aos bens 
culturais, é escassa na jurisprudência brasileira, principalmente por não ter sido levada, em muitas oportunidades, à apreciação.

Dessa maneira, é válida a citação de um julgado do Poder Judiciário da Argentina, o qual é tido por leading case de repercussão internacional, que trata da reparação por danos morais causados por consequência da violação ao patrimônio cultural. Cuida-se de um acórdão, prolatado em 22/10/1996, pela Câmara de Apelações Cíveis e Comerciais, Sala A, envolvendo o Município de Tandil e a empresa T.A. La Estrella S/A.

No caso concreto, um ônibus da empresa deslocou-se, sem condutor, por uma rua da cidade e colidiu-se com uma fonte e um grupo escultórico chamado Las Nereidas, provocando danos de monta nesses bens culturais. Assim, o Município de Tandil ingressou com uma ação, buscando a reparação dos prejuízos patrimoniais experimentados pelo Município (valor dos materiais e mão de obra necessários à restauração dos bens, além da diminuição do valor venal do conjunto), além de indenização pelos danos morais causados a toda a comunidade tandilense.

O Tribunal da Província considerou que a comunidade local merecia ser indenizada, pelo dano moral, em razão da privação do gozo estético que estaria a justificar o cuidado com a ornamentação urbana. Sendo assim, procedente o pedido, condenando a empresa a pagar $\$ 30.000$ pesos pelos danos patrimoniais e $\$ 1.500$ pesos pelo dano moral.

\footnotetext{
Nesse sentido, portanto, destaca-se a jurisprudência argentina que concebe o dano moral de toda uma coletividade afetada, quando a lesão é sobre um bem de natureza extrapatrimonial e coletiva, a relação de causalidade com um critério probabilístico, a imprescritibilidade das ações de prevenção e recomposição do dano ambiental coletivo e as categorias de dano ambiental coletivo e dano ambiental individual ${ }^{29}$.
}

No Brasil, ao julgar o Recurso Especial (REsp) n. 598.281, no ano de 2006, o Superior Tribunal de Justiça examinou a possibilidade de caracterização do dano moral coletivo decorrente de lesão ao meio ambiente, reconhecendo se tratar de um tema polêmico e sobre o qual jurisprudência ainda não havia se sedimentado. A questão tinha por base um recurso do Ministério Público do Estado de Minas Gerais, em que figuraram como recorridos o Município de Uberlândia e uma empresa que explorava o ramo de empreendimentos imobiliários. O Ministério Público havia aforado ação civil pública, com o escopo de paralisar a implantação

${ }^{29}$ SILVEIRA, 2008, p. 39. 
de um loteamento, pleiteando a reparação dos danos materiais causados ao meio ambiente, além de indenização em dinheiro a título de danos morais coletivos.

A ação civil pública teve seus pedidos julgados procedentes em primeira instância, mas em sede de apelação o Tribunal de Justiça de Minas Gerais excluiu a indenização por danos morais coletivos, que havia sido fixada pela sentença em $\mathrm{R} \$ 50.000,00$ para cada réu, articulando que o dano moral é todo sofrimento causado ao indivíduo em decorrência de qualquer agressão aos atributos da personalidade ou a seus valores pessoais, logo de caráter individual, inexistindo qualquer previsão de que a coletividade possa ser sujeito passivo do dano moral.

Em face disso, o Ministério Público interpôs REsp, postulando o restabelecimento da decisão da sentença, sustentando que o Artigo $1^{\circ}$ da LACP prevê a possibilidade de que a coletividade seja sujeito passivo de dano moral. Articulou que o direito ao meio ambiente ecologicamente equilibrado pertence à coletividade de maneira autônoma e indivisível e que sua lesão atinge, concomitantemente, a pessoa no seu status de indivíduo relativamente à quota-parte de cada um e, de forma mais ampla, toda a coletividade.

O Ministro Relator do REsp, Luiz Fux, deu provimento ao recurso. Na sua compreensão, o meio ambiente tem, hodiernamente, valor inestimável para a humanidade, tendo, por isso, alcançado a eminência de garantia constitucional. Ele entendeu que a nova redação dada à $\mathrm{CF} / 1988$, quanto à proteção ao dano moral, possibilitou ultrapassar a barreira do indivíduo e abranger o dano extrapatrimonial à pessoa jurídica e à coletividade. Assim, restabelecia a sentença, inclusive no que diz com o valor da indenização. Segue a ementa:

AÇÃO CIVIL PÚBLICA. DANO AO MEIO AMBIENTE. DANO MATERIAL E MORAL. ART. $1^{\circ}$ DA LEI 7347/85.

$[\ldots]$

2. O meio ambiente ostenta na modernidade valor inestimável para a humanidade, tendo por isso alcançado a eminência de garantia constitucional.

3. $\mathrm{O}$ advento do novel ordenamento constitucional - no que concerne à proteção ao dano moral - possibilitou ultrapassar a barreira do indivíduo para abranger o dano extrapatrimonial à pessoa jurídica e à coletividade.

7. O dano moral ambiental caracterizar-se (sic) quando, além dessa repercussão física no patrimônio ambiental, sucede ofensa ao sentimento difuso ou coletivo - v.g.: 
o dano causado a uma paisagem causa impacto no sentimento da comunidade de determinada região, quer como v.g; a supressão de certas árvores na zona urbana ou localizadas na mata próxima ao perímetro urbano.

8. Consectariamente, o reconhecimento do dano moral ambiental não está umbilicalmente ligado à repercussão física no meio ambiente, mas, ao revés, relacionado à transgressão do sentimento coletivo, consubstanciado no sofrimento da comunidade, ou do grupo social, diante de determinada lesão ambiental.

9. Destarte, não se pode olvidar que o meio ambiente pertence a todos, porquanto a Carta Magna de 1988 universalizou este direito, erigindo-o como um bem de uso comum do povo. Desta sorte, em se tratando de proteção ao meio ambiente, podem co-existir o dano patrimonial e o dano moral, interpretação que prestigia a real exegese da Constituição em favor de um ambiente sadio e equilibrado.

10. Sob o enfoque infraconstitucional a Lei n. 8.884/94 introduziu alteração na LACP, segundo a qual passou restou expresso que a ação civil pública objetiva a responsabilidade por danos morais e patrimoniais causados a quaisquer dos valores transindividuais de que cuida a lei.

11. Outrossim, a partir da Constituição de 1988, há duas esferas de reparação: a patrimonial e a moral, gerando a possibilidade de o cidadão responder pelo dano patrimonial causado e também, cumulativamente, pelo dano moral, um independente do outro.

12. Recurso especial provido para condenar os recorridos ao pagamento de dano moral, decorrente da ilicitude perpetrada contra o meio ambiente, nos termos em que fixado na sentença.

Houve o acompanhamento do voto pelo Ministro José Delgado. Entretanto, o entendimento que prevaleceu na Turma foi o do Ministro Teori Albino Zavascki, que foi seguido pela Ministra Denise Arruda e pelo Ministro Francisco Falcão. Para Zavascki, o dano ambiental ou ecológico pode, em tese, acarretar dano moral. Todavia, a vítima do dano moral seria, necessariamente, uma pessoa. Não pareceria ser compatível com o dano moral a ideia da transindividualidade (indeterminabilidade do sujeito passivo e da indivisibilidade da ofensa e da reparação) da lesão ${ }^{30}$. Ao contrário do afirmado pelo Ministério Público, por conseguinte, seria perfeitamente viável a tutela do bem jurídico salvaguardado pelo Artigo 225 da CF/1988, tal como realizada na ação civil pública, mediante a determinação de providências que assegurem a restauração do ecossistema degradado, sem

\footnotetext{
${ }^{30}$ Em sentido contrário, registre-se que o próprio STJ sumulou: 227 - A pessoa jurídica pode sofrer dano moral.
} 
qualquer referência a um dano moral, aventou o Ministro.

Principalmente em função dessa manifestação do STJ, há divergência quanto à ocorrência de dano moral coletivo em razão de lesões ao patrimônio cultural. A título ilustrativo, o Tribunal de Justiça de Minas Gerais, local de origem da discussão antes referida, divide-se, conforme se percebe nas seguintes ementas:

APELAÇÃO CÍVEL. AÇÃO CIVIL PÚBLICA. EVENTO DESPROVIDO DE SEGURANÇA ADEQUADA. DANO MORAL COLETIVO. IMPOSSIBILIDADE IN CASU. O dano moral se dirige a uma pessoa ofendida em sua personalidade, de forma individual, subjetiva e psíquica, sendo sua natureza incompatível com a transindividualidade própria da tutela dos interesses coletivos. Recurso conhecido e não provido. (AC No 1.0338.06.045943-9/001, Rel. Des. Elias Camilo e Kildare Carvalho, Julgada em: 13/05/2010)

Ação Civil Pública - Demolição de Prédio - Tombamento Provisório - Arquivamento do Processo - Legalidade - Poder Judiciário - verificação do aspecto legal do ato - Pedido de Indenização por dano moral coletivo - Impossibilidade - Recurso Desprovido. (AC N ${ }^{\circ}$ 1.0702.04.147510-5/001, Rel. Des. Kildare Carvalho, Julgada em: $25 / 10 / 2007)$.

Na primeira ementa resta claro que o entendimento é no sentido de que as ideias de dano moral e transindividualidade não se conciliam. Enquanto, na outra ementa, curiosamente tendo por relator o mesmo desembargador, seria possível a concessão do pedido indenizatório pelo dano moral coletivo, desde que houvesse sido demonstrada a ofensa ao sentimento coletivo, ou seja, de valores compartilhados pela coletividade, caracterizando dano aos interesses extrapatrimoniais dos membros de um grupo ou coletividade, a ensejar a indenização que atenda a toda a comunidade atingida pelo evento danoso.

Passa-se, então, à análise dos casos concretos, os quais tratam com exclusividade do objeto desta pesquisa, permitindo comprovar a veracidade da problematização proposta neste trabalho. 


\section{EXAME DA JURISPRUDÊNCIA DOS TRIBUNAIS DE JUSTIÇA DOS ESTADOS}

Segundo Castro (1997, p. 150), o Judiciário brasileiro, sobretudo após 1988, passou a interagir com o sistema político num processo complexo, do qual participam: a) os tribunais judiciais, especialmente o STF; b) governo e partidos políticos; c) associações profissionais relevantes, especialmente a Associação dos Magistrados Brasileiros e a Associação Juízes para a Democracia, que têm orientações, valores e concepções distintas acerca do papel institucional do Poder Judiciário; e d) a opinião pública.

Nesse cenário, nos termos de Vianna, Burgos e Salles ${ }^{31}$ : “É da cena contemporânea de cultura democrática a projeção do papel do juiz em quase todos os aspectos da vida social". No tocante, então, ao que se concebe por judicialização, entende-se ser ela resultado do aumento da provocação do Poder Judiciário, na direção de atuar, assegurando o resguardo de um direito indicado em lei, podendo essa ação suprir eventual lacuna que os Poderes Executivo e Legislativo deixaram de promover, ou conferir novos entendimentos jurisprudenciais, com base em problemas identificados em casos concretos.

Outro ponto relevante é a distinção entre judicialização da política e ativismo judicial. Nesse caminho de reflexão será utilizada uma definição normativamente inerte de "ativismo judicial". A prática jurídica mostra que magistrados ativistas podem tanto adotar um posicionamento progressista quanto uma decisão conservadora. Ao mesmo tempo, não é possível afirmar, de antemão, que uma atitude ativista seja sempre a atitude correta ou incorreta diante de todos os casos jurídicos possíveis, especialmente em casos difíceis.

Neste sentido, em uma primeira acepção, o ativismo judicial será medido pela frequência com que um determinado magistrado ou tribunal invalida as ações (normas e atos normativos) de outros poderes de Estado, especialmente do Poder Legislativo [...]. Ou seja, com que frequência os tribunais retiram a decisão das mãos dos eleitores [...]. Além disso, também será considerado ativista o magistrado ou tribunal que procura suprir omissões (reais ou aparentes) dos demais poderes com suas decisões, como, por exemplo, no tocante à definição ou concretização de políticas públicas ou regulamentação das regras do jogo democrático ${ }^{32}$.

\footnotetext{
${ }^{31}$ VIANNA; BURGOS; SALLES, 2006, p. 1.
}

${ }^{32}$ SILVA et al., 2008, p. 57, 58. 
Ainda de acordo com Castro $^{33}$, a judicialização da política corresponde a um fenômeno observado em diversas sociedades contemporâneas, que apresenta dois componentes: 1) um novo "ativismo judicial", isto é, uma nova disposição de tribunais judiciais no sentido de expandir o escopo das questões sobre as quais eles devem formar juízos jurisprudenciais (muitas dessas questões até recentemente ficavam reservadas ao tratamento dado pelo Legislativo ou pelo Executivo); e 2) o interesse de políticos quanto às autoridades administrativas adotarem (a) procedimentos semelhantes àqueles do processo judicial e (b) parâmetros jurisprudenciais em suas deliberações (muitas vezes, o Judiciário é politicamente provocado a fornecer esses parâmetros).

A constituição do corpo deste estudo se deu, além dos aportes teóricos já citados e trabalhados, por meio de busca no sítio eletrônico de cada Tribunal de Justiça estadual brasileiro, considerando os vinte e seis Estados e o Distrito Federal e Territórios, com a utilização dos critérios (ou verbetes) "patrimônio e cultural e dano e moral e coletivo", inseridos nos campos "pesquisa livre", "busca livre", "palavras-chave" e "pesquisa genérica" de cada um deles, fazendo a busca de acórdãos (decisões colegiadas) e decisões monocráticas (decisão diretamente proferida pelo relator) que contivessem as palavras/expressões desejadas no seu inteiro teor. $\mathrm{O}$ período utilizado foi desde a disponibilização dos acórdãos na internet por cada Tribunal até fevereiro de 2012, inclusive.

No caso, foram inseridos apenas os parâmetros de pesquisa "patrimônio e cultural", a fim de contabilizar quantas decisões envolvendo o tema foram proferidas em cada órgão. Após, foram inseridos os demais parâmetros de pesquisa ("patrimônio e cultural e dano e moral e coletivo"), com o intuito de se identificar se essa temática havia sido superada pelo Tribunal respectivo.

No entanto, após essa pesquisa, verificou-se que os verbetes, embora estivessem explicitados no texto da decisão, acabavam por trazer à tona as mais diferentes matérias: indenizatórias por ofensa a direito de personalidade e por plano de saúde, responsabilidade civil por acidente de trânsito, improbidade administrativa, entre outras. Isso obrigou a realização de um filtro em que apenas fossem resultantes as decisões vinculadas ao dano moral coletivo decorrente da violação do patrimônio cultural. O

${ }^{33}$ CASTRO, 1997, p. 149. 
filtro, nesse sentido, foi a análise, caso a caso, observacional, da matéria tratada em cada uma das decisões resultantes da pesquisa "patrimônio e cultural e dano e moral e coletivo".

Refere-se, igualmente, que foram feitas inúmeras tentativas, com as mais diversas combinações de verbetes; entretanto esta indicada aqui foi a que se revelou mais abrangente no resultado das buscas providenciadas.

Nesse contexto, elaborou-se a Tabela 2, que traz o número de decisões dos Tribunais de Justiça estaduais brasileiros, envolvendo o Patrimônio Cultural (PC), bem como esse e o Dano Moral Coletivo (DMC), e o produto da pesquisa (filtrada).

\begin{tabular}{|c|c|c|c|c|}
\hline $\begin{array}{c}\text { Tribunal de } \\
\text { Justiça }\end{array}$ & Desde & PC & $\begin{array}{c}\text { PC e } \\
\text { DMC }\end{array}$ & Filtrada \\
\hline Acre & 1996 & 21 & 4 & 1 \\
\hline Alagoas & 1996 & 0 & 0 & 0 \\
\hline Amapá & 2005 & 17 & 0 & 0 \\
\hline Amazonas & 2001 & 1 & 0 & 0 \\
\hline Bahia & 2000 & 3 & 0 & 0 \\
\hline Ceará & 1995 & 77 & 2 & 0 \\
\hline $\begin{array}{c}\text { Distrito } \\
\text { Federal e } \\
\text { Territórios }\end{array}$ & 1997 & 74 & 1 & 0 \\
\hline Espírito Santo & 2002 & 51 & 3 & 0 \\
\hline Goiás & 2004 & 19 & 1 & 0 \\
\hline Maranhão & 2002 & 16 & 1 & 1 \\
\hline Mato Grosso & 2005 & 9 & 8 & 0 \\
\hline Mato Grosso & 2001 & 401 & 12 & 0 \\
\hline do Sul & & & & 0 \\
\hline Minas Gerais & 2000 & 3.834 & 101 & 0 \\
\hline Pará & 2002 & 11 & 0 & 0 \\
\hline Paraíba & 2005 & 3 & 0 & 0 \\
\hline Paraná & 1968 & 1.410 & 323 & 0 \\
\hline Pernanbuco & 1961 & 3 & 0 & 0 \\
\hline Piauí & 2002 & 0 & 0 & 0 \\
\hline Rio de Janeiro & 1975 & 85 & 2 & 0 \\
\hline
\end{tabular}




\begin{tabular}{|c|c|c|c|c|}
\hline $\begin{array}{c}\text { Rio Grande } \\
\text { do Norte }\end{array}$ & 2000 & 42 & 3 & 0 \\
\hline $\begin{array}{c}\text { Rio Grande } \\
\text { do Sul }\end{array}$ & 1965 & 134 & 2 & 0 \\
\hline Rondônia & 2002 & 17 & 0 & 0 \\
\hline Roraima & 2005 & 3 & 0 & 0 \\
\hline $\begin{array}{c}\text { Santa } \\
\text { Catarina }\end{array}$ & 2002 & 1.682 & 105 & 0 \\
\hline São Paulo & 1977 & 4.210 & 107 & 0 \\
\hline Sergipe & 2000 & 220 & 21 & 0 \\
\hline Tocantins & 2005 & 0 & 0 & 0 \\
\hline
\end{tabular}

Tabela 1: Número de decisões dos Tribunais de Justiça estaduais brasileiros envolvendo o Patrimônio Cultural (PC), bem como esse e o Dano Moral Coletivo (DMC), e o produto da pesquisa (filtrada), desde o ano indicado até fevereiro de 2012.

Conquanto se soubesse que a aplicação da temática proposta é, de fato, incipiente, foi surpreende o fato de, no Brasil, conforme a pesquisa realizada, haver apenas duas decisões que tenham por aplicar a indenização por dano moral coletivo em face de lesões ocasionadas aos bens culturais: uma proveniente do Acre e a outra do Maranhão, as quais serão, em seguida, apreciadas.

Tal estranheza se identifica com a ampliação do trato do patrimônio cultural, conforme explica Poulot ${ }^{34}$ :

Quando o patrimônio se "naturaliza" como comemoração da vitalidade de qualquer cultura, o território apresenta-se, assim, o lugar comum dessa afirmação. Ainda há pouco tempo, a presença de monumentos de todas as ordens, de edifícios prestigiosos e de prédios "antigos" é que transformava o território em um patrimônio, ao passo que, atualmente, qualquer território pode ser declarado patrimônio, de acordo com a nova perspectiva de uma ética que preconiza o reconhecimento mundial de culturas.

Outro ponto que chama muito a atenção é o fato de que em alguns Estados sequer há menção ao patrimônio cultural nas decisões dos Tribunais, caso de Alagoas, Piauí e Tocantins. É realmente singular, mas,

${ }^{34}$ POULOT, 2009, p. 227, 228. 
de qualquer sorte, eventual equívoco na realização de ementas fica superado, visto que a pesquisa se deu no inteiro teor dos julgamentos. Então, duas situações são possíveis, a saber; a primeira, no sentido que esse tipo de matéria (ao menos com essa especificação nominal) não foi proposta para análise, ou, como bem destaca Birnfeld ${ }^{35}$ :

\begin{abstract}
[...] uma constatação que não pode deixar de ser feita no que tange a proliferância da legislação ambiental nacional é a que diz respeito à sua escassa aplicação pelos operadores jurídicos em geral, a qual pode ser justificada em parte pela existência de um conjunto às vezes confuso de disposições, em parte pela existência de lacunas importantes no próprio conjunto normativo, mas principalmente e em grande parte pelo escasso grau de importância que os próprios operadores jurídicos destinam geralmente às questões atinentes à legislação ambiental, demonstrando um lamentável desconhecimento dos valores críticos que estão nela inseridos, quando não demonstram (o que é pior ainda) um pleno desconhecimento das próprias normas ambientais.
\end{abstract}

Sob outro prisma, percebe-se que São Paulo e Minas Gerais são os Tribunais de Justiça que mais produzem em assuntos relacionados ao patrimônio cultural, seguidos, respectivamente, por Santa Catarina e Paraná, os quais, entretanto, embora tenham imensa vantagem diante dos demais, ficam abaixo por mais do dobro dos julgamentos proferidos que transitam com o tema patrimônio cultural.

Além disso, cabe fazer referência ao Tribunal de Justiça do Paraná, quanto às decisões que disseram respeito ao patrimônio cultural em conjunto com o dano moral coletivo, as quais foram em número de 323, triplo no número obtido na grande maioria dos demais Tribunais. Contudo, verificando cuidadosamente essas decisões, obteve-se a resposta para isso: foram dezenas de julgamentos (pontuais) com pedido de indenização por dano moral individual (de particular contra indústria petrolífera), decorrente de dano ambiental (rompimento de poliduto ou vazamento de nafta petroquímica), que suspendeu a pesca e outras extrações marinhas por mais de 30 dias.

Feitas as observações necessárias, passa-se à análise das duas decisões citadas (Acre e Maranhão), assim ementadas, respectivamente:

APELAÇÃO CÍVEL. TOMBAMENTO. IMÓVEL LOCALIZADO EM SÍTIO HISTÓRICO. AUSÊNCIA DE NOTIFICAÇÃO DOS PROPRIETÁRIOS. DEMO-

${ }^{35}$ BIRNFELD, 2006, p. 255, 256. 
LIÇÃO. INDENIZAÇÃO CABÍVEL. VALOR CORRETAMENTE FIXADO. (AC No 9.448 - Rio Branco, Rel. Desa. Izaura Maia, Julgada em: 15/03/2011).

APELAÇÃO CÍVEL. AÇÃO CIVIL PÚBLICA. PATRIMÔNIO HISTÓRICO CULTURAL. REVESTIMENTO ASFÁLTICO. RUAS TOMBADAS. DANO EXTRAPATRIMONIAL COLETIVO.

I - O dano patrimonial e o dano extrapatrimonial decorrentes de ofensa ao bem cultural são distintos, o primeiro incide sobre interesses de natureza material ou econômica, refletindo-se no patrimônio do lesado, e o segundo refere-se aos valores de ordem moral. Assim, cabível a fixação desses danos conjuntamente.

II - Caracterizado o dano extrapatrimonial decorrente do revestimento asfáltico em ruas tombadas, através de competente Decreto Estadual, como patrimônio histórico, devida é a reparação do dano. (AC N 1.345/2010 - São Luís, Rel. Des. Jorge Rachid Mubárack Maluf, Julgada em: 20/05/2010).

Quanto ao acórdão do Acre.

Cuidou-se de Apelações Cíveis interpostas pela Fundação de Cultura e Comunicação Elias Mansour e pelo Ministério Público do Estado do Acre no intuito de reformar sentença proferida pelo Juízo de Direito da $2^{\text {a }}$ Vara da Fazenda Pública da Comarca de Rio Branco que, julgando a Ação Civil Pública n. 001.09.005048-8, proposta pelo Ministério Público, condenou a Fundação de Cultura e Comunicação Elias Mansour e Fundação Municipal de Cultura Garibaldi Brasil, solidariamente, ao pagamento de indenização pelos danos morais causados à coletividade no valor de $\mathrm{R} \$$ 50.000,00, a ser revertido em favor do Fundo de Pesquisa e Preservação do Patrimônio Cultural do Estado Acre; à obrigação de fazer consistente em realizar, no prazo de 24 meses, o inventário geral dos bens de caráter histórico, cultural e arquitetônico relevantes para a constituição do acervo cultural rio-branquense, cuja preservação e conservação sejam de interesse público, na forma do Art. $9^{\circ}$, inc. III, da Lei Estadual n. 1.145/1994, visando ao tombamento desses bens, após a deliberação do Conselho do Patrimônio Cultural do Acre, bem como tomar todas as medidas necessárias à proteção dos referidos bens, tutelando-os adequadamente, através do competente tombamento, que deverá ser realizado no prazo de 24 meses.

Unanimemente, foram desprovidos os recursos, ficando mantida a decisão do juízo de primeira instância, conforme referido. Cabe indicar apenas que a apelação proposta pelo Ministério Público foi na direção de tentar aumentar o arbitramento do caso moral para $\mathrm{R} \$ 500.000,00$. Entre- 
tanto, foi negado o aumento, sob o fundamento de terem sido consideradas todas as particularidades do caso no momento da aplicação da indenização moral.

Quanto ao acórdão do Maranhão.

Tratou-se de Apelação Cível interposta pelo Município de São Luís contra a sentença proferida pelo Juiz de Direito da $2^{\mathrm{a}}$ Vara da Fazenda Pública da Comarca da Capital, Dr. Carlos Henrique Rodrigues Veloso, que julgou procedente a Ação Civil Pública n. 19.667/2002 ajuizada pelo Ministério Público Estadual. O juiz julgou procedentes os pedidos formulados na inicial para condenar o Município a proceder à restauração da Rua do Machado e de todos os demais logradouros do Centro Histórico de São Luís, tombados no Decreto n. 10.089/86, a partir do início de sua vigência e que tiveram o calçamento revestido por camada asfáltica sem autorização do Órgão do Patrimônio Histórico, Artístico e Paisagístico Estadual, recompondo as características originais e compatíveis com os usos necessários pela população, no prazo máximo de quatro anos. Para o caso de descumprimento, arbitrou multa diária de $\mathrm{R} \$ 1.000,00$ (um mil reais), a contar do término do prazo acima concedido, em favor do órgão citado, além de indenização por danos extrapatrimoniais no valor de $\mathrm{R} \$ 3.508,73$ (três mil quinhentos e oito reais e setenta e três centavos). Salientou o magistrado que tais medidas seriam necessárias para proteger o patrimônio histórico-cultural, além de destacar a possibilidade da cumulação de pedidos de obrigação de fazer e indenização por danos extrapatrimoniais. O Município recorreu da sentença, na parte em que o condenou em danos extrapatrimoniais, por entender estarem ausentes os requisitos para tanto, pois a pavimentação da Rua do Machado teria sido requerida pela própria população. Ademais, houve a restituição ao seu status quo ante, razão pela qual requereu a exclusão da condenação. Ressaltou, ainda, a impossibilidade de cumulação de obrigação de fazer com obrigação de pagar. Nas contrarrazões, o Ministério Público Estadual ressaltou a possibilidade da condenação em danos extrapatrimoniais, decorrente não apenas do sentimento de dor, mas da utilidade que certos bens e valores possuem ao desenvolvimento de uma sociedade.

Assim, como na decisão anterior, foi unânime a negativa do provimento ao apelo. De qualquer modo, muito bem ponderada a manutenção do dano moral arbitrado, ao indicar que a responsabilização pelos danos causados ao patrimônio cultural de uma cidade tem duas finalidades, uma preventiva, ou seja, busca induzir o agente a evitar o dano, e, a segunda, 
repressiva, determina àquele que gerar o dano ambiental a obrigação de repará-lo, concluindo-se que o dano patrimonial e o extrapatrimonial são distintos, o primeiro incide sobre interesses de natureza material ou econômica, refletindo-se no patrimônio do lesado, e o segundo refere-se aos valores de ordem moral e espiritual, podendo as duas modalidades ser fixadas conjuntamente.

Portanto, como exposto ao longo da fundamentação teórica, bem como, por ora, amparando-a em casos práticos, está demonstrada a plena viabilidade do arbitramento de dano moral coletivo em decorrência de violações aos bens culturais, tratando-se, inclusive pelo resultado da busca realizada nos bancos de dados dos Tribunais de Justiça estaduais, de um mecanismo, na prática, incipiente, mas, ao mesmo tempo, inovador na tentativa de obstaculizar e/ou dificultar os ataques ao patrimônio cultural.

Além disso, como bem pontua Candau ${ }^{36}$, é possível estabelecer uma continuidade simbólica entre o passado e o futuro, a lembrança e o esquecimento, mantendo a memória coletiva, permitindo-se construir passados alternativos, sendo fundamental para a maneira de perceber-se e perceber sua identidade, por meio desse instrumento de proteção do patrimônio cultural, que passa a ganhar contornos mais definidos.

\section{CONCLUSÃO}

O patrimônio cultural, enquanto um direito difuso, tanto para o Poder Público como para os particulares, é sempre indisponível e deve ser preservado, em especial, tendo em conta as gerações do porvir. Dessa maneira, o direito a todos aos bens culturais diz respeito não apenas à guarda, preservação e proteção desses bens, mas também à sua promoção, nela se inserindo o direito de acesso e fruição pela coletividade em geral, diante de sua titularidade difusa.

A responsabilidade pela violação das normas de acautelamento do patrimônio cultural é objetiva, isto é, independe da existência de culpa. A coletividade, por sua vez, em face de um prejuízo causado ao patrimônio cultural, evidentemente pode ser afetada quanto a seus valores imateriais, diante do sentimento coletivo de desapreço, de intranquilidade, de angústia, de indignação e de demonstração de aviltamento ao direito. Assim, a aplicação da responsabilidade civil em razão de danos morais coletivos é,

$\overline{{ }^{36} \text { CANDAU, 2011, p. } 166 .}$ 
certamente, uma sanção garantidora do restabelecimento dignidade social, ao mesmo tempo em que funciona como medida de caráter preventivo, por representar a ampliação da possibilidade de responsabilização do agente.

Nesse contexto, a produção no tocante à caracterização da responsabilidade civil, em decorrência de danos morais coletivos ocasionados por lesões aos bens culturais, é ainda escassa na jurisprudência estadual brasileira, mormente por não ter sido levada, em muitas oportunidades, à apreciação. De qualquer forma, a análise da jurisprudência estadual brasileira comprovou que se está muito aquém, ainda, acerca da produção em termos ambientais, em especial sobre o tema do patrimônio cultural, e que a indenização por dano moral coletivo ante lesões a bens culturais é, sim, viável juridicamente, sendo mais uma ferramenta à disposição para proteção e promoção do patrimônio cultural do Brasil.

\section{REFERÊNCIAS}

AVILA, Mônica Maranghelli. A reparação do dano ambiental e fundos. MPRS, p. 1-22, 2011.

BIRNFELD, Carlos André Hüning. Cidadania ecológica: fundamentos para a compreensão da emergência e do significado do Estado de bem-estar ambiental e do direito ambiental. Pelotas: Delfos, 2006.

CAFFERATTA, Néstor A. Breves reflexiones sobre la naturaleza del daño ambiental colectivo. R. CEJ, Brasília, n. 29, p. 21-26, abr./jun. 2005.

CANDAU, Joël. Memória e identidade. São Paulo: Contexto, 2011.

CARVALHO, Délton Winter de. Dano ambiental futuro: a responsabilização civil pelo risco ambiental. 1. ed. Rio de Janeiro: Forense Universitária, 2008.

CASTRO, Marcos Faro de. O Supremo Tribunal Federal e a judicialização da política. Revista Brasileira de Ciências Sociais, v. 12, n. 34, jun. 1997, p. $147-156$.

FREITAS, Cristina Godoy de Araújo. Valoração do dano ambiental: algumas premissas. MPMG Jurídico, Belo Horizonte, p. 10-17, 2011.

LEITE, José Rubens Morato. Dano ambiental: do individual ao coletivo extrapatrimonial. 2. ed. São Paulo: RT, 2003. 
MILARÉ, Edis. Direito do ambiente: doutrina, jurisprudência, glossário. 5. ed. São Paulo: Revista dos Tribunais, 2007.

MIRANDA, Marcos Paulo de Souza. Tutela do patrimônio cultural brasileiro: doutrina - jurisprudência - legislação. Belo Horizonte: Del Rey, 2006.

. Configuração e indenizabilidade de danos morais coletivos decorrentes de lesões a bens integrantes do patrimônio cultural brasileiro. Revista de Direito Ambiental, a. 14, n. 54, p. 229-253, abr./jun. 2009.

POULOT, Dominique. Uma história do patrimônio no Ocidente, séculos XVIII-XXI: do monumento aos valores. São Paulo: Estação Liberdade, 2009.

SILVA, Alexandre Garrido da; MEDEIROS, Bernardo Abreu de; PESSANHA, Daniella dos Santos; CHALOUB, Jorge Gomes de Souza; VIEIRA, José Ribas. Revista da Faculdade de Direito de Uberlândia, v. 36, 2008, p. 53-78.

VIANNA, Luiz Werneck; BURGOS, Marcelo Baumann; SALLES, Paula Martins. Dezessete anos de judicialização da política. Cadernos CEDES, Rio de Janeiro, n. 8, dez. 2008, p. 1-71.

Recebido: 22/09/2013

Aceito: 20/11/2013 